Ebisu Ebisu

Études japonaises Études japonaises

57 | 2020

Les architectes de l'ère Heisei (1989-2019). Rôles, statuts, pratiques et productions

\title{
LUCKEN Michael, Le Japon grec. Culture et possession
}

Paris, Gallimard, collection «Bibliothèque des Histoires », 2019, 250 p.

\section{Marie-Elisabeth Mitsou}

\section{(2) OpenEdition}

\section{Journals}

Édition électronique

URL : http://journals.openedition.org/ebisu/5447

DOI : $10.4000 /$ ebisu. 5447

ISSN : 2189-1893

Éditeur

Institut français de recherche sur le Japon à la Maison franco-japonaise (UMIFRE 19 MEAE-CNRS)

Édition imprimée

Date de publication : 15 décembre 2020

Pagination : 451-454

ISSN : 1340-3656

\section{Référence électronique}

Marie-Elisabeth Mitsou, « LUCKEN Michael, Le Japon grec. Culture et possession», Ebisu [En ligne], 57 | 2020, mis en ligne le 20 décembre 2020, consulté le 29 mars 2021. URL : http:// journals.openedition.org/ebisu/5447 ; DOl : https://doi.org/10.4000/ebisu.5447 


\section{LuCKen Michael,}

Le Japon grec. Culture et possession, Paris, Gallimard, collection

"Bibliothèque des Histoires ", 2019, 250 p.

Ces dernières années, une série d'études remarquables sur le philhellénisme est parue en France ${ }^{1}$. Tous ces ouvrages confirment le rôle privilégié de l'Allemagne, non seulement dans la découverte de la Grèce antique, mais surtout dans la formation du Griechenmythos (mythe grec). L'idéal artistique des Grecs établi par Johann Joachim Winckelmann dès le $\mathrm{xvIII}^{\mathrm{e}}$ siècle, leur perfection originelle investie dans le projet néo-humaniste de Wilhelm von Humboldt, l'affinité linguistique et la parenté spirituelle entre Grecs et Allemands, la constitution de l'Altertumswissenschaft (science de l'antiquité), toutes ces constructions déboucheront, à partir des premières décennies du XIX ${ }^{e}$ siècle, sur une "obsession philhellénique"; elles deviendront un destin pour l'Allemagne ${ }^{2}$. Plus qu'un modèle culturel, la Grèce éternelle s'est avérée un élément déterminant dans la formation nationale allemande.

Par rapport à l'hellénomanie allemande, l'attachement des autres pays occidentaux à la Grèce classique semble plutôt secondaire. Quant au reste du monde, aux pays asiatiques et au Japon en particulier, de très rares informations sont fournies dans la bibliographie philhellénique. Il a été question, par exemple, du poète et traducteur gréco-irlandais, Lafcadio Hearn, naturalisé japonais en 1896 sous le nom de Koizumi Yakumo 小泉八雲 (1850-1904), qui représente un médiateur culturel grécojaponais. Professeur de littérature anglaise à l'université impériale de Tokyo puis à l'université de Waseda, converti au bouddhisme et intégré parfaitement à la culture nippone, Koizumi Yakumo n'avait pourtant d'autre rapport avec la Grèce que sa mère, Rosa Kassimati, et son lieu de naissance, Leucade. Aussi cette île ionienne était encore placée sous le protectorat britannique. Or, certaines références dans son œuvre, et bien plus encore les pavements de mosaïques et les colonnes antiques du parc commémoratif Koizumi Yakumo dans le quartier de Shinjuku à Tokyo évoquent la passion du célèbre écrivain pour son pays natal (p. 31-32, 149).

Le lecteur du Japon grec de Michael Lucken constate en revanche que la Grèce du Japon n'est ni l'effet du hasard ni un sujet marginal de l'histoire culturelle transnationale. Il se 
trouve au contraire que "l'Antiquité gréco-romaine fait partie des fondements de la culture du Japon contemporain " (p. 20). Vu qu'aucun rapport direct n'était connu entre les deux pays lointains, la Grèce et le Japon, ni même par l'intermédiaire de l'archéologie ou des collections d'art, ce livre d'érudition surprend tout d'abord par son titre. Michael Lucken n'hésite pas à désigner cette association de mots comme une chimère, " un être hybride composé de deux parties qui ne correspondent pas " (p. 12), mais qui se révèle au fur et à mesure une réalité historique étonnante.

Le Japon serait-il donc la Grèce de l'Asie au même titre que l'Allemagne se représentait comme la Grèce nordique? En quoi ce « mythe grec japonais " consiste-t-il et quel objectif la référence grecque japonaise pouvait-elle servir? Dans trois chapitres encadrés par une introduction et une conclusion très éclairantes, ainsi que trois dialogues fictifs entre un "suffisant lecteur" et trois couples d'écrivains japonais qui ont marqué les études grecques japonaises, l'auteur de cet ouvrage passionnant se lance sur des pistes inédites $\mathrm{du}$ philhellénisme japonais, d'un philhellénisme esthétisant, commercial et savant. Il dresse un inventaire des références grecques dans tous les domaines des sciences humaines et sociales, des beaux-arts et des arts de la scène; il propose une périodisation de ce transfert singulier, une étude prosopographique des intellectuels hellénisants et une généalogie des usages de la Grèce dans l'archipel japonais.

Le bilan de cette étude minutieuse et originale du Japon grec est impressionnant : divers récits des origines, plusieurs théories de filiation et de parenté intellectuelle et linguistique, images gréco-bouddhiques, empreintes grecques dans l'architecture, la peinture, la sculpture, le théâtre, le cinéma, la danse, un nombre considérable de noms d'origine grecque, de traductions d'œuvres philosophiques, historiques, mythologiques, littéraires, de postes académiques, d'éditions, de colloques et de revues scientifiques ${ }^{3}$. Cependant, Le Japon grec ne se limite pas à la réception de la culture grecque et son histoire plurielle dans l'Archipel. Il ne présente pas seulement un panorama périodisé des hellénistes et des hellénismes japonais entre le $\mathrm{XVI}^{\mathrm{e}}$ siècle et l'époque contemporaine; il se veut aussi un instrument de lecture et d'interprétation des cultures dites périphériques et des échanges culturels entre l'Occident et l'Orient. Lapproche de Michael Lucken repose sur deux principes épistémologiques: le premier concerne le 
rapport centre-périphérie, entendu, d'ordinaire, comme rapport de domination et de transfert unilatéral; le second émane d'une réflexion sur la notion de possession dans le monde de la culture.

À première vue, le lecteur s'imagine que la référence grecque du Japon est calquée sur celle de l'Europe, plus précisément sur l'exemple de l'Allemagne. La preuve, l'Altertumswissenschaft prédomine dans l'entre-deux-guerres et la prédilection pour les lettres classiques est plus forte chez des intellectuels japonais qui se réclament du militarisme, du totalitarisme, voire du national-socialisme (p. 104-110). Dans une perspective postcoloniale, l'appropriation des classiques gréco-latins ne pourrait être, en effet, que le résultat de la colonisation culturelle de l'Occident sur le Japon - d'un pur mimétisme (para)colonial. Cette assertion implique toutefois que l'intérêt des cultures européennes pour la Grèce est naturel et évident, qu'il n'est pas l'effet du transfert de textes et d'antiquités en Europe de l'Ouest, et que les Occidentaux sont, par conséquent, les seuls héritiers légitimes de l'Antiquité gréco-latine (p. 15, 18), excluant toute autre relation non médiatisée avec les sources, même celle des Grecs modernes, qui sont, eux aussi, victimes de l'hégémonisme culturel européen ${ }^{4}$.
La réalité, comme pour tout transfert culturel, est évidemment beaucoup plus complexe. Malgré la distance géographique, l'absence de collections d'antiquités et la rareté de l'expérience du terrain, le rapprochement des Japonais à la Grèce est incontestable. Même si cette Grèce japonaise « est plus asiatique qu'européenne, dionysiaque quapollinienne, polythéiste que chrétienne, archipélagique que continentale " (p. 124), elle n'en est pas moins une Grèce transférée et réappropriée selon les besoins d'un contexte nouveau, donc une Grèce authentique. «Transférer, ce n'est pas transporter, mais plutôt métamorphoser ", nous a appris Michel Espagne. "C'est moins la circulation des biens culturels que leur réinterprétation qui est en jeu ${ }^{5}$."

Le Japon grec de Michael Lucken est, dans ce sens, un excellent exemple de transferts culturels et de l'imagination en tant qu'outil de la possession. La Grèce de l'Allemagne comme celle du Japon sont des constructions modernes différentes, mais également légitimes et autrement intéressantes. Comme disait Pierre Bourdieu, "beaucoup de malentendus dans la communication internationale viennent $\mathrm{du}$ fait que les textes n'emportent pas leur contexte avec eux ${ }^{6}$ ». Dans le cas du Japon grec, textes et contextes 
s'entrelacent et s'expliquent mutuellement, pour révéler une assimilation des savoirs et des arts grecs plus autonome peut-être, mais aussi possessive qu'en Europe occidentale et un philhellénisme plus rationnel et plus équilibré que celui qui nous est familier.

\section{Marie-Elisabeth Mitsou Directrice d'études EHESS}

1. Espagne Michel et Pécout Gilles (dir.), Philhellénismes et transferts culturels dans l'Europe du XIXe siècle, 2005 : 1-2 (http://rgi. revues.org/62); Barau Denys, La Cause des Grecs. Une histoire du mouvement philhellène (1821-1829), Paris, Honoré Champion, 2009; Maufroy Sandrine, Le Philhellénisme franco-allemand (1815-1848), Paris, Belin, 2011; Mazurel Hervé, Vertiges de la guerre. Byron, les philhellènes et le mirage grec, Paris, Les Belles Lettres, 2013; Andurand Anthony, Le Mythe grec allemand. Histoire d'une affinité élective, Rennes, Presses universitaires de Rennes, 2014; Chapoutot Johann, Le Nazisme et l'Antiquité, Paris, Presses universitaires de France, 2012. Cette liste n'est pas exhaustive.

2. Marchand Suzanne L., Down from Olympus. Archaeology and Philhellenism in Germany 1750-1970, Princeton, Princeton University Press, 1996, p. xxxvi ; Andurand Anthony, op. cit. : 19-22, 25.

3. "Il semblerait même que, depuis les années 1990, il y ait davantage de professeurs de grec dans l'enseignement supérieur $\mathrm{au}$ Japon qu'en Grande-Bretagne » (p. 117). 4. L'anthropologue Michael Herzfeld, spécialiste de la Grèce, a introduit le terme de crypto-colonialisme; voir "The Absent Presence: Discourses of
Crypto-Colonialism ", South-Atlantic Quarterly, octobre 2002, 101 (4) : 899-926. Sur l'interprétation essentialiste des cultures périphériques, la réponse de Michael Lucken est catégorique: "De gré ou de force, les cultures s'entrelacent et se transforment sans qu'aucun retour en arrière ne soit jamais possible» (p. 16).

5. Michel Espagne, "La notion de transfert culturel ", Revue Sciences/Lettres, 2013, 1 (https://journals.openedition.org/rsl/219).

6. Bourdieu Pierre, "Les conditions sociales de la circulation internationale des idées ", Actes de la recherche en sciences sociales, 145 (5), $2002: 4$. 